\title{
Peripheral Blood Immune Response Elicited by Beta-Lactoglobulin in Childhood Cow's Milk Allergy
}

\author{
IMMACOLATA VOCCA, ROBERTO BERNI CANANI, ALESSANDRA CAMARCA, SERENA RUOTOLO, RITA NOCERINO, \\ GIORGIA RADANO, ANDREA DEL MASTRO, RICCARDO TRONCONE, AND CARMEN GIANFRANI
}

Institute of Food Sciences [I.V., A.C., G.R., C.G.], CNR, Avellino 83100, Italy; Department of Pediatrics and European Laboratory for the Investigation of Food-Induced Diseases [R.B.C., S.R., R.N., A.D.M., R.T.], University "Federico II" of Naples, Naples 80131, Italy

\begin{abstract}
Several studies analyzing the immune responses in patients with cow's milk allergy (CMA) have used T-cell lines or $\mathrm{T}$-cell clones that require prolonged in vitro cell culturing and may result in a switched cell phenotype and function. We investigated immune responses to beta-lactoglobulin (b-LG) in peripheral blood mononuclear cells after a short in vitro antigen stimulation in children with acute CMA (both IgE-mediated and non-IgE-mediated forms) and in those who outgrew an IgE-mediated CMA. Healthy controls were also investigated. Peripheral blood mononuclear cells were assayed for IL-13, IFN- $\gamma$, IL-4, and IL-10. Although b-LG induced a cytokine production and/or cell proliferation almost in all children, included healthy controls, differences were observed among the four groups. Children with IgE-mediated CMA had a marked Th2-response, with high IL-13 production and proliferation, but low IFN- $\gamma$; by contrast, children with non-IgE-mediated CMA produced no, or very low, IL-13 and cell proliferation. Children, who outgrew CMA, showed a shift to a Th1-response, with reduced IL-13 and increased IFN- $\gamma$. IL-10-responses were high in all groups, with the highest level in healthy children; by contrast, IL-4 was undetectable in all children. This study highlights the use of shortly stimulated peripheral blood cells to investigate the food-induced immune responses. (Pediatr Res 70: 549-554, 2011)
\end{abstract}

A llergy to cow's milk proteins (CMP) is one of the most common food allergies (FA) in the developed countries elicited by an IgE- or non-IgE-mediated mechanism $(1,2)$. The major allergens of cow's milk $(\mathrm{CM})$ are betalactoglobulin (b-LG) and alpha-S1-casein, as indicated by large population studies (3). These proteins are also highly resistant to proteolysis by gastrointestinal enzymes, resulting in large peptides at the site of mucosal immune system with implications for immune reactivity and cow's milk allergy (CMA) emergence (4).

Profile of immune responses to the main CMP is not completely understood, particularly in those patients affected by gastrointestinal, non-IgE-mediated, forms of CMA (2). Furthermore, a consistent number of the studies investigating the immune responses to CMP, and to food allergens in general, have used T-cell lines or T-cell clones, mostly derived from peripheral blood mononuclear cells (PBMCs) (5-12). Albeit these are powerful techniques to investigate

Received February 7, 2011; accepted July 6, 2011.

Correspondence: Carmen Gianfrani, Ph.D., Institute of Food Sciences-CNR, Via Roma 64, 83100, Avellino, Italy; e-mail: cgianfrani@isa.cnr.it

Supported by Regione Campania POR RT05B.

The authors report no conflicts of interest. immune response to several antigens, and to define the stimulatory sequences in complex antigenic proteins, manipulation can occur in long-term cell cultures that could result in alteration of cell phenotypes and functions. $\mathrm{T}$ cells producing IL-4 and IL-13 (Th2-phenotype) were described in children with acute IgE-CMA (6), whereas CMP-specific, IFN- $\gamma$ releasing cells (Th1-skewed phenotype) were described in infants without CMA (6). Marked T-cell proliferation to CMP occurs in the great majority of subjects, independently of a positive CMA diagnosis (13).

Children with CMA (either IgE- or non-IgE-mediated) spontaneously outgrow allergy (14), rendering this alimentary disorder an important model to study the mechanisms that mediate the immune tolerance to CMP and to food antigens in general. IL-10-producing $\operatorname{Tr} 1$ and CD4+CD25+ regulatory T (Treg) cells have been suggested to play a key role in tolerance acquisition in CMA children $(5,15)$. Although it has been reported that Treg cells are not impaired in their suppressive function during allergic diseases (16), and both healthy and allergic individuals exhibit all three allergen-specific T-cell subsets (Th1, Th2, and Treg), it is likely that allergic condition results from an inappropriate balance between Treg and T-effector responses $(13,17-19)$.

In this study, we comparatively analyzed the profile of immune reactivity to $b-L G$ in four different groups of children: 1) with IgE-mediated CMA; 2) with non-IgE-mediated CMA; 3) who have outgrown IgE-mediated CMA; and 4) healthy controls with no history of any FA. IL-13, IL-4, IL-10, IFN- $\gamma$, and cell proliferation were evaluated in fresh PBMCs after a short in vitro stimulation with b-LG, thus avoiding prolonged cell culturing and undesired cell manipulation. The HLA restriction and the role of IL-10 in controlling the peripheral immune responses to $\mathrm{b}-\mathrm{LG}$ were also investigated.

\section{PATIENTS AND METHODS}

Study subjects. Twenty-eight patients with a diagnosis of CMA were enrolled: 14 with IgE-mediated CMA and 14 with non-IgE-mediated CMA. They had been on elimination diet for $10.2 \mathrm{mo}$ (range, 6-16 mo) and $8.9 \mathrm{mo}$ (range, 6-14 mo), respectively. For comparison, nine children who have

Abbreviations: b-LG, beta-lactoglobulin; CM, cow's milk; CMA, cow's milk allergy; CMP, cow's milk proteins; ELISPOT, enzyme-linked immunosorbent spot; EU, endotoxin units; FA, food allergy; LPS, lipopolysaccharide; PBMCs, peripheral blood mononuclear cells; PHA, phytohemagglutinin; SFC, spot-forming cells; SI, stimulation index; Treg, regulatory T cells 
Table 1. Main demographic and clinical characteristics of the study population

\begin{tabular}{|c|c|c|c|c|}
\hline & $\begin{array}{l}\text { Healthy } \\
\text { controls }\end{array}$ & $\begin{array}{l}\text { IgE-mediated } \\
\text { CMA }\end{array}$ & $\begin{array}{l}\text { Non-IgE-mediated } \\
\text { CMA }\end{array}$ & $\begin{array}{c}\text { Tolerant, ex } \\
\text { IgE-mediated CMA }\end{array}$ \\
\hline$N$ & 14 & 14 & 14 & 9 \\
\hline Male, $n(\%)$ & $9(64.2)$ & $11(73.3)$ & $8(57.1)$ & $8(88.8)$ \\
\hline Age in months, median (range) & $39.2(6-81)$ & $40.4(10-66)$ & $26.1(6-89)$ & $49.7(19-138)$ \\
\hline $\begin{array}{l}\text { Age in months at the onset of food allergy-related } \\
\text { symptoms: median }(95 \% \mathrm{CI})\end{array}$ & - & $9.8(7.2-14.7)$ & $7.4(6.7-11.7)$ & $8.5(5.9-12.8)$ \\
\hline \multicolumn{5}{|l|}{ Symptoms* } \\
\hline Eczema & - & $10(71.4)$ & $9(64.2)$ & $9(100)$ \\
\hline Angioedema-urticaria & - & $8(57.1)$ & $0(0.0)$ & $7(78)$ \\
\hline Gastrointestinal & - & $8(57.1)$ & $14(100)$ & $5(55.5)$ \\
\hline Laryngospasm & - & $1(7.1)$ & $0(0.0)$ & $0(0.0)$ \\
\hline Anaphylaxis & - & $2(14.2)$ & $0(0.0)$ & $0(0.0)$ \\
\hline Total serum $\operatorname{IgE}(\mathrm{kU} / \mathrm{l})($ mean $\pm \mathrm{SD}) \dagger$ & $<0.35$ & $196.9 \pm 140$ & $14.7 \pm 15.9$ & $57.9 \pm 33.4$ \\
\hline Cow's milk-specific IgE $(\mathrm{kU} / \mathrm{l})($ mean value $\pm \mathrm{SD}) \dagger$ & $<0.35$ & $21.1 \pm 17.7$ & $0.5 \pm 0.7$ & $3.1 \pm 2.7$ \\
\hline Cow's milk SPT weal $(\mathrm{mm})$ (mean value $\pm \mathrm{SD})$ & - & $6.5 \pm 1.2$ & - & $2.2 \pm 1.4$ \\
\hline Cow's milk APT positive, $n(\%)$ & - & - & $10(71.4)$ & - \\
\hline
\end{tabular}

* Symptoms are referred to the time of CMA diagnosis.

$\dagger$ Total serum IgE and cow's milk-specific IgE were measured using a commercially available kit (CAP-RAST, Pharmacia Diagnostics AB, Uppsala, Sweden). The positive cutoff value was 0.35 , all healthy controls showed results below this cutoff value.

APT, atopic patch test; kU, kilo units; SPT, skin prick test.

-, not applicable.

outgrown IgE-mediated CMA and consumed CM regularly since at least 6 mo and 14 healthy controls who consumed at least one full cup of CM daily, were also evaluated. Exclusion criteria were chronic systemic diseases, congenital cardiac defects, active tuberculosis, autoimmune diseases, immunodeficiency, chronic inflammatory bowel diseases, celiac disease, cystic fibrosis, metabolic diseases, or malignancy. Control children were enrolled among subjects visiting the Center for routine examinations or for minimal surgical procedures. These children met the same inclusion and exclusion criteria, except that they did not have a history of FA, neither of atopy, and were serum negative for CMP-specific IgE. Main demographic and clinical characteristics of the enrolled children are reported in Table 1. The diagnosis of CMA was obtained in our Department assessing: 1) clinical history; 2) the results of allergen-specific IgE titers, skin prick, and patch tests; and 3) the result of the oral food challenge, as previously described (20). All food challenges were performed within 3 mo before study entry, in a double-blind placebocontrolled manner (DBPFC), and took place in the outpatients clinic of our Department on two separate days with a 1-wk interval. The results were assessed by two experienced pediatric allergists. Briefly, every $20 \mathrm{~min}$, fresh pasteurized $\mathrm{CM}(0.1,0.3,1,3,10,30$, and $100 \mathrm{~mL})$ containing $3.5 \%$ fat or placebo (Neocate, Nutricia Italia $\mathrm{SpA}$ ) were administered. Study subjects were scored for nine items divided into four main categories (general, skin, gastrointestinal, and respiratory) on a 0 - to 3 -point scale ( 0 , none; 1 , light; 2 , moderate; and 3 , severe). If both investigators independently scored any item at level 3 or 2 (or more) items at level 2, the test result was considered positive. Parents of infants taking an antihistamine were advised to withhold the treatment for $72 \mathrm{~h}$ before and during the challenge. The child was observed for $2 \mathrm{~h}$ after the final dose and then discharged. The tested formula $(100 \mathrm{~mL} / \mathrm{d})$ was given by the parents at home for $7 \mathrm{~d}$. If any symptoms occurred during this period, the patients returned to the outpatient clinic on the same day. On d 7, all infants were examined and the parents interviewed at the Department. An oral food challenge was repeated every 6 mo until the appearance of oral tolerance. The results of allergic screening tests and oral food challenge were registered into a specific clinical chart. Approval for the study was obtained from the Ethics Committee of the Medical School at the University of Naples "Federico II," and written informed consent was obtained from parents of each child enrolled in the study.

Isolation of PBMCs and functional assays. All children were evaluated in stable clinical conditions without fever or any acute illness in the last 3 wk. At the enrollment of each study subject, a venous blood sample $(5-8 \mathrm{~mL})$ was collected in a heparinized tube. PBMCs were isolated from blood samples by Ficoll gradient. After washing, cells were resuspended in X-VIVO containing $5 \%$ heat-inactivated, human $\mathrm{AB}$ sera (BioWhittaker-Lonza) at a density of $2 \times 10^{5} / 200 \mu \mathrm{L} /$ well for functional assays. Cells were stimulated with b-LG (100 $\mu \mathrm{g} / \mathrm{mL})$, BSA $(100 \mu \mathrm{g} / \mathrm{mL})$, or phytohemagglutinin (PHA; $2 \mu \mathrm{g} / \mathrm{mL}$ ). IFN- $\gamma$, IL-4, and IL- 10 were analyzed by a $36-40 \mathrm{~h}$ enzyme-linked immunosorbent spot (ELISPOT) assay, or by $48 \mathrm{~h}$ ELISA, as previously described (21). The levels of IL-13 were evaluated in cell supernatants by a $48 \mathrm{~h}$ ELISA assay. ELISPOT results are shown as net spot-forming cells (SFC; number of
SFC detected in the presence of antigen minus SFC detected with the medium alone) on the total of cells plated. Sensitivity of ELISA assays was as follows: $125 \mathrm{pg} / \mathrm{mL}$ for IL-13, $63 \mathrm{pg} / \mathrm{mL}$ for IFN- $\gamma$, and $9 \mathrm{pg} / \mathrm{mL}$ for IL-4. Results are shown as net of cytokine concentration. In the experiments with blocking anti-IL-10R and anti-DR/DQ MAbs, PBMCs were preincubated for $10 \mathrm{~min}$ with $10 \mu \mathrm{g} / \mathrm{mL}$ of each MAbs, before the addition of antigens. All experimental points were done in duplicates.

Proliferation assays. PBMCs were incubated for $6 \mathrm{~d}$ in the presence or absence of indicated antigens. The cultures were thereafter pulsed with 0.5 $\mu \mathrm{Ci}\left[{ }^{3} \mathrm{H}\right]$-thymidine (Amersham-Pharmacia, Milan, Italy) and incubated for additional $9 \mathrm{~h}$ before the $\left[{ }^{3} \mathrm{H}\right]$ incorporated in the DNA was measured by liquid scintillation counting (TopCount, Packard, Canberra). Results were shown as stimulation index (SI), i.e. cpm in cells stimulated with antigens divided by cpm in cells stimulated with medium alone.

Antigens and antibodies. b-LG and BSA were purchased from Sigma Chemical Co. (Sigma Chemical Co.-Aldrich, Milan, Italy). Antigens were tested for lipopolysaccharide (LPS) content by the Limulus Amebocite Lysate kit (BioWhittaker-Lonza, Basel, Switzerland) according to the manufacturer's instructions. LPS content is expressed as endotoxin units (EU)/mg of protein (1 EU corresponds approximately to $100 \mathrm{pg}$ of LPS). PHA was purchased from Roche (Milan Italy). Anti-IL-4R blocking MAb (MAb) was from R\&D System (Milan, Italy). Both purified and biotinylated anti-IFN- $\gamma$, IL-4, and IL-13 MAbs were from e-Bioscience (San Diego, CA); specific capture and detection anti-IL-10 antibodies were from Endogen (San Diego, CA); anti-DQ MAb (clone SPV-L3) from Biodesign International (Saco, ME); anti-IL-10R (clone 3F9) and anti-DR MAbs (clone L243) were purchased from PharMingen-BD (Milan, Italy)

Statistics. Data are presented as median (interquartile range). Comparison between groups was performed by nonparametric two tailed Mann-Whitney $U$ test using SPSS version 16.0 for Windows (SPSS, Inc., Chicago, IL). The $p<0.05$ was considered significant.

\section{RESULTS}

Cytokine Production Profile of Peripheral Blood Cells in Response to $\boldsymbol{b}-\boldsymbol{L G}$. To investigate the cytokine and proliferative response elicited by the ingestion of $\mathrm{CM}$ in children with a positive history of CMA, we have stimulated freshly isolated PBMCs with b-LG, one of the main allergen of CMP or with BSA as control protein. Cell activation was evaluated after $2 \mathrm{~d}$ (for cytokine production) or $6 \mathrm{~d}$ (for cell proliferation): this procedure allowed us to monitor secondary immune responses, most likely primed in vivo after allergen exposure. Because we have analyzed PBMCs' immune reactivity either 


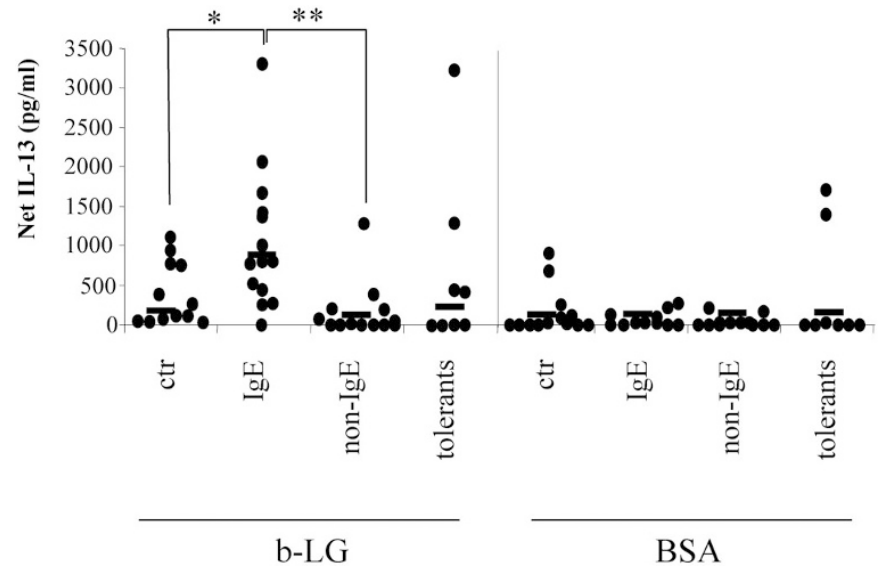

Figure 1. IL-13 production of PBMCs in response to b-LG and BSA. Antigen-specific production of IL-13 was evaluated in PBMCs of 13 healthy controls (ctr), 14 children with IgE-mediated CMA (IgE), 14 children with non-IgE-mediated CMA (non-IgE), and 8 children who have outgrown an IgE-mediated CMA (tolerants). Fresh PBMCs $\left(2 \times 10^{5} /\right.$ well $)$ were stimulated with b-LG and BSA $(100 \mu \mathrm{g} / \mathrm{mL})$, and after $48 \mathrm{~h}$, the level of IL-13 was measured in cell supernatants by a sandwich ELISA. Horizontal bars represent the median values obtained within each group. Significance was determined using the nonparametric Mann-Whitney $U$ test comparing allergic or tolerant groups with healthy controls or between them. $* * p<0.015, * p<0.05$.

in individuals with CMA (IgE- or non-IgE-mediated), and in children who became tolerant, or who have never experienced an allergic reaction to $\mathrm{CMP}$, and in which the immune responses are supposed to be weak or not expected at all, we have chosen as read-out the very sensitive ELISPOT assay to detect antigen-specific cellular response for IFN- $\gamma$, IL-4, and IL-10. Instead, IL-13 was analyzed by ELISA because of the technical limitations we had in studying this cytokine by ELISPOT.

IL-13. We aimed to investigate whether IL-13 is produced by PBMCs of allergic children in response to $b-L G$. As shown in Figure 1, the IL-13 production was significantly increased in patients with IgE-mediated CMA: median (interquartile range) $785.5(257.1-1274.2) \mathrm{pg} / \mathrm{mL}$, compared with subjects with non-IgE-mediated CMA: $37.0(0.0-198.25) \mathrm{pg} / \mathrm{mL}$ or with healthy controls: $117.1(46.1-657.8) \mathrm{pg} / \mathrm{mL}(p<0.015$ and $p<0.05$, respectively). Although two tolerant patients produced relatively high amount of IL-13 in response to b-LG, the amount of this cytokine detected in clinically tolerant children, $232.0(18.7-647.5) \mathrm{pg} / \mathrm{mL}$, was much less than the level in children on acute disease, albeit the difference did not reach a statistical significance. The stimulation with BSA did not induce significant IL-13 production in any of the four groups analyzed, except few subjects who resulted responsive in control and in tolerant groups.

$I F N-\gamma$. Overall, we found very low number of IFN- $\gamma$ producing cells in PBMCs in response to a short stimulation with b-LG in all four groups analyzed: median (interquartile range) of net IFN- $\gamma$-SFC/ $2 \times 10^{5}$ cells: 5.5 (1.3-27.0). Children who recovered an IgE-mediated CMA displayed the highest number of IFN- $\gamma$-producing cells: 41.0 (21.0-47.5), significantly higher compared with children with acute IgECMA: 1.0 (0.0-3.6), $p<0.05$, (Fig. $2 A$ ). Low IFN- $\gamma$ -
A
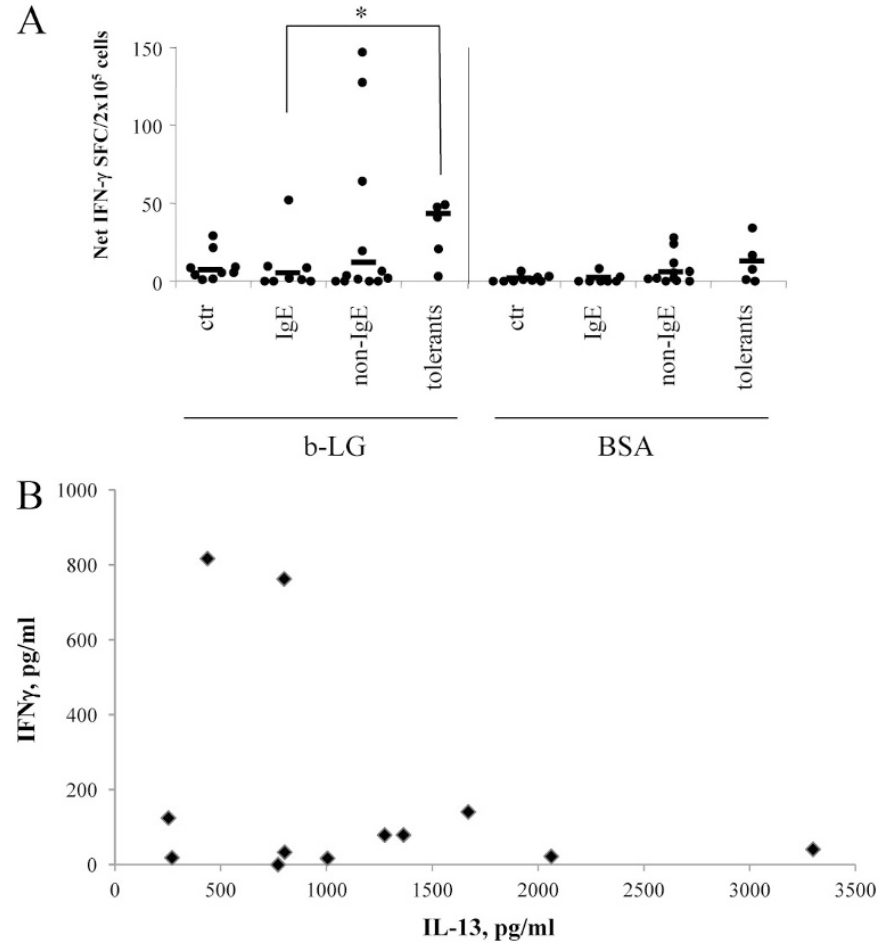

Figure 2. IFN- $\gamma$ production of PBMCs in response to b-LG and BSA. (A) IFN- $\gamma$-secreting cells were evaluated in peripheral blood of children with CMA (8 IgE- and 12 non-IgE-mediated) of 5 tolerants and of 9 healthy controls on allergen stimulation; $2 \times 10^{5}$ PBMCs were stimulated with b-LG and BSA $(100 \mu \mathrm{g} / \mathrm{mL})$ and IFN- $\gamma$-producing cells detected by $36-40 \mathrm{~h}$ ELISPOT-assay. Horizontal bars represent the median value within each group $(* p<0.05)$. $(B)$ IFN- $\gamma$ and IL-13 production in response to b-LG stimulation $(100 \mu \mathrm{g} / \mathrm{mL})$ was analyzed in PBMCs from 12 children with IgE-mediated CMA. Cytokine levels were measured in cell supernatants as described in Figure 1.

responses to b-LG were observed in non-IgE-allergic children, except few subjects: 5.0 (1.8-34.4). By contrast, the control protein BSA did not recall any substantial IFN- $\gamma$-response.

Because children with IgE-mediated CMA displayed, as a whole group, a very low number of IFN- $\gamma$-secreting cells, and conversely a very high IL-13 production upon b-LG stimulation, to better compare these two cytokine responses, we analyzed the level of IFN- $\gamma$ in PBMCs supernatants by ELISA in 12 children, previously analyzed by ELISPOT (Fig. $2 B$ ). In 10 of 12 children, the production of IFN- $\gamma$ resulted very low (below $150 \mathrm{pg} / \mathrm{mL}$ ), if compared with the level of IL-13, (range, 250.0-3300.0 pg/mL), confirming the trend observed in the IFN- $\gamma$-ELISPOT (Fig. $2 A$ ).

$I \boldsymbol{L}$-4. In this study, we were not able to detect any significant IL-4 production in peripheral blood in response to b-LG or BSA, either by ELISPOT or ELISA (data not shown). No better results were obtained after optimizing the assay through the use of an antibody blocking the IL-4 receptor (data not shown). A defect in either IL-4 production in PBMCs or in IL-4 assay procedures can be excluded because PBMCs incubated with the polyclonal activator PHA secreted high level of this cytokine (data not shown).

$\boldsymbol{I L}$-10. IL-10-producing cells were consistently detected in PBMCs of all groups after stimulation with b-LG and at very high frequencies: median (interquartile range) of net IL-10- 


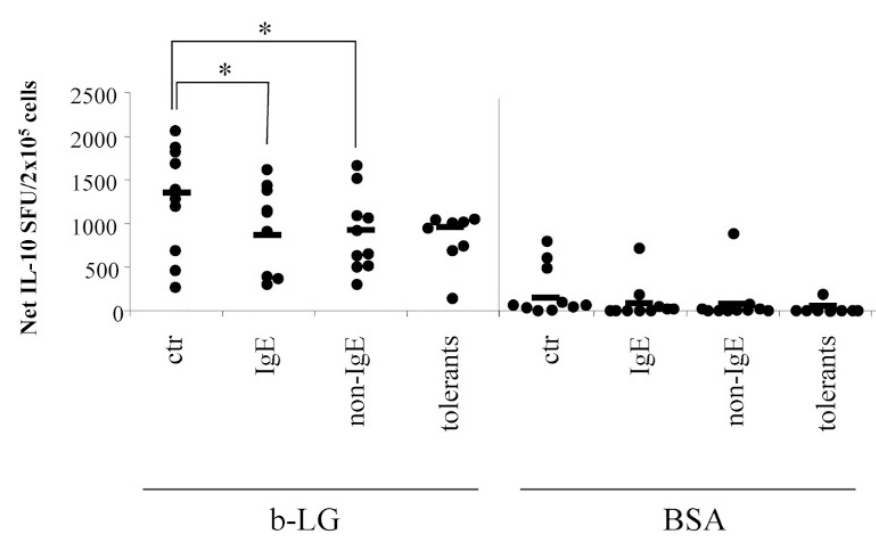

Figure 3. IL-10 production of PBMCs in response to b-LG and BSA. Antigen-specific, IL-10-secreting cells were evaluated in PBMCs from CMA children (11 IgE- and 13 non-IgE-mediated), 8 tolerants, and 10 healthy controls; $2 \times 10^{5}$ PBMCs were stimulated with b-LG or BSA $(100 \mu \mathrm{g} / \mathrm{mL})$ and assayed by ELISPOT after 36-40 h. Horizontal bars represent the median value within each group. ${ }^{*} p<0.05$.

SFC/ $2 \times 10^{5}$ cells: $915.0(503.0-1187.0)$. Healthy children showed the highest number of IL-10-producing cells in response to b-LG: 1333.0 (815.0-1755.5; Fig. 3), and similarly to IFN- $\gamma$ - and IL-13-responses, IL-10-producing cells were not detectable against BSA in any of the four groups analyzed, if excepted few subjects.

To dissect if LPS contamination found in b-LG preparations, $\sim 20 \mathrm{EU} / \mathrm{mg}$ of protein, could affect the cytokine production in our study population, we performed preliminary experiments using PBMCs from adult healthy donors and escalating dose of LPS. We found that LPS at the concentration detected in our antigen samples induced the production of IL-10, while no IL-4, IL-13, and IFN- $\gamma$ were produced. Furthermore, LPS contamination accounted for only a part of the high IL-10 production observed in PBMCs (data not shown).

Proliferative Response of PBMCs to $\boldsymbol{b}$-LG. The rate of PBMC proliferation to $\mathrm{b}-\mathrm{LG}$ was analyzed $6 \mathrm{~d}$ after the allergen stimulation of PBMCs by looking at $\left[{ }^{3} \mathrm{H}\right]$-thymidine incorporation in the DNA. When we looked at the proliferation in each single subject (selecting a $\mathrm{SI} \geq 3$, as cutoff for positive response), we found that subjects responsive to b-LG were present in all groups, including the healthy donors. Nevertheless, children with IgE-mediated CMA showed the highest cell proliferation rate: median (interquartile range) 7.0 (3.0-9.8), compared with controls: $2.4(1.8-4.5)$ and with patients with non-IgE-mediated CMA: $2.6(1.9-3.9 ; p<0.05$, Fig. 4).

PBMCs Response to b-LG is HLA-Class II-Restricted and Is Increased by Blocking $I \boldsymbol{L}-\mathbf{1 0}$. We next evaluated whether HLA-class II restricts the PBMCs responses to b-LG. Because of the limited availability of blood samples, the HLA restriction was assessed by using a cocktail of antibodies blocking the HLA-DQ and HLA-DR molecules in four IgE-mediated and in five non-IgE-mediated allergic children. As shown in Figure $5 A$, the proliferative responses to b-LG were significantly reduced in the presence of the neutralizing antibodies in all patients analyzed $(p<0.0001)$. These results indicated that b-LG specifically induced proliferation of circulating $\mathrm{T}$ cells

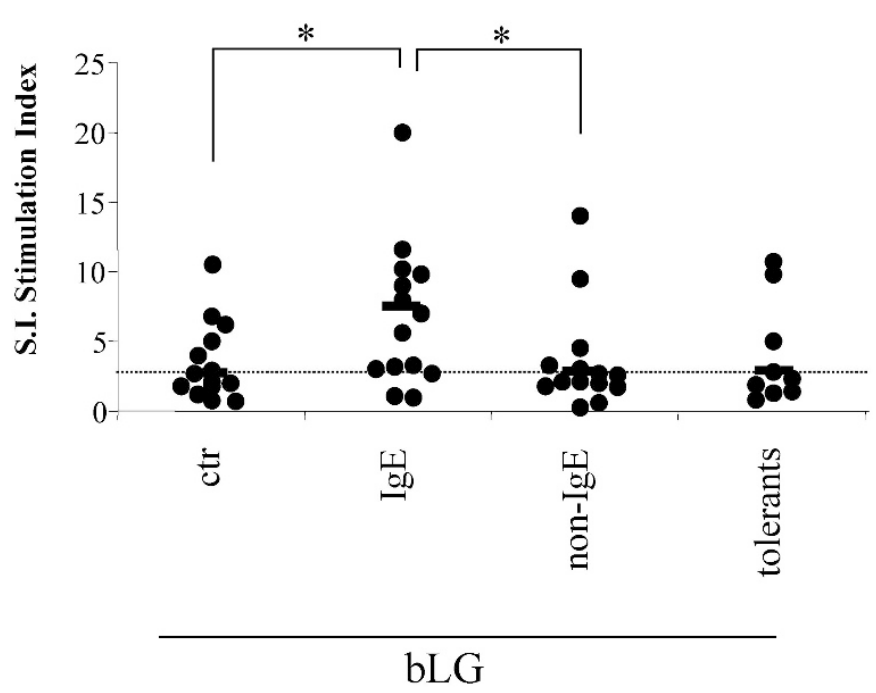

Figure 4. Proliferative response of PBMCs to b-LG. b-LG-specific, proliferative response in PBMCs from CMA children (14 IgE- and 14 non-IgEmediated), from 9 children who outgrew IgE-CMA, and from 14 healthy controls. PBMCs were incubated with b-LG as reported in Figure 1, and the rate of cell proliferation was determined $6 \mathrm{~d}$ after by labeling cells with 0.5 $\mu \mathrm{Ci}\left[{ }^{3} \mathrm{H}\right]$ thymidine/well. Values are shown as SI. Proliferative responses were considered positive when SI was $\geq 3$. Horizontal bars represent the average SI among patients of each group. The broken line indicates the cutoff value for positive response. ${ }^{*} p<0.05$.

and that HLA-DQ/DR molecules play a substantial role in recalling secondary cell responses in peripheral blood of CMA children.

To further address whether IL-10, found highly upregulated in PBMCs in the great majority of subjects analyzed, might have a regulatory effect, we stimulated cells from both allergic and tolerant children with b-LG in the presence or absence of antibody blocking the IL-10 receptor. Remarkably, the blocking of IL-10 activity caused an increase of cell proliferation to b-LG ranging from 1.3- to 7.6-folds compared with the responses of not treated cells $(p<0.05$; Fig. $5 B)$.

\section{DISCUSSION}

This study shows that following a brief in vitro stimulation, b-LG-specific cell responses can be recalled in peripheral blood of children affected by CMA and of tolerant or nonallergic, healthy children. Although b-LG stimulation induced an immune reactivity in PBMCs of the great majority of analyzed children (93\% up to $100 \%$ of subjects showed a positive response, as cytokine secretion and/or cell proliferation), differences among the groups occurred. Children with IgE-mediated CMA produced significantly higher IL-13 compared with healthy children and with children with non-IgEmediated CMA. Conversely, tolerance to CMP was associated with a marked reduction of IL-13 production and a concomitant increased frequency of b-LG-specific, IFN- $\gamma$-releasing cells. Children with IgE-mediated CMA showed the highest rate of proliferation to $b-\mathrm{LG}$. This suggested that an immediate clinical reaction to milk ingestion, typical of IgE-mediated allergy, might be associated with a prompted in vivo T-cell proliferation to $\mathrm{b}-\mathrm{LG}$, and the marked reduction of T-cell 
A
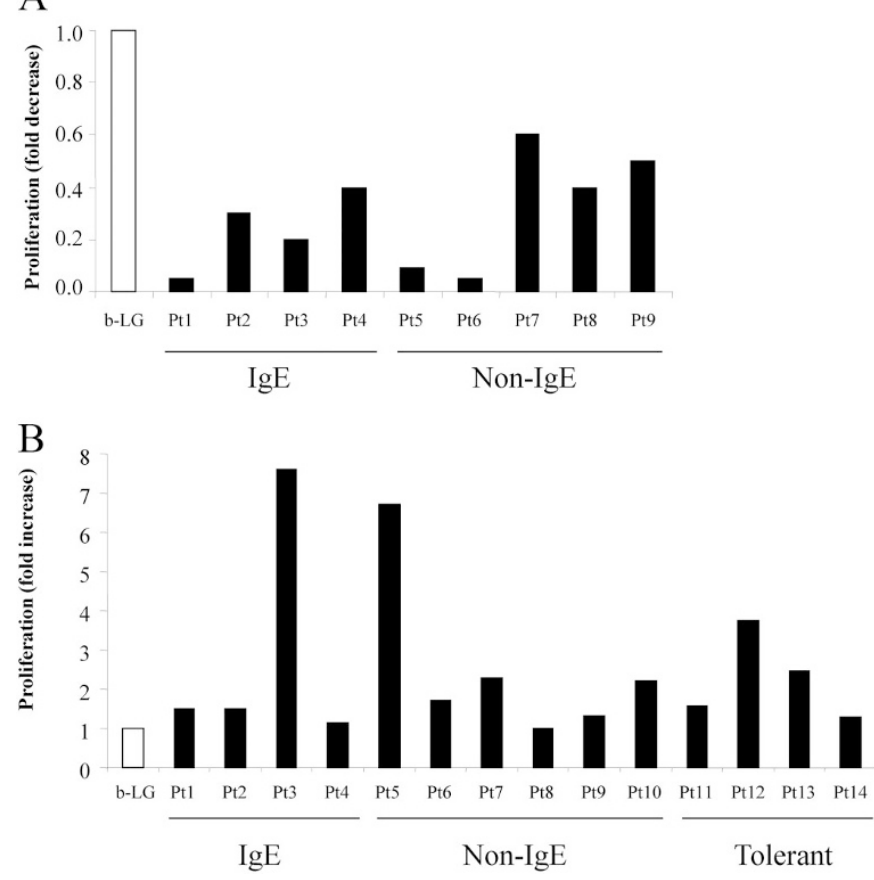

Figure 5. Proliferative response of PBMCs to b-LG in the presence of blocking MAbs. Effect of anti-HLA-class II antibodies (A) and of anti-IL-10 receptor $(B)$ MAbs on the proliferative response to b-LG in PBMCs from CMA allergic or tolerant patients. Proliferative responses, evaluated as SI, to b-LG in the presence of indicated blocking antibody ( $\square$ ) are normalized with the response observed with b-LG alone (SI $=1, \square)$.

proliferation to b-LG in children who acquired tolerance to CMP corroborates this finding.

Collectively, the profile of immune responses to b-LG in freshly isolated PBMCs are consistent with previous reports done with long-lasting T-cell cultures and showing a polarized Th2-responses, with a marked IL-13 production, in acute IgE-mediated FA, and a Th1-skewed cytokine pattern, with IFN- $\gamma$ production, in non-IgE-mediated forms $(5,6)$. We were not able to detect any specific production of IL-4 in any of analyzed subjects and this was in contrast with previous reports $(5,12)$. This discrepancy can be explained by the fact that our experimental design is not sufficient to recall a detectable IL-4 response in peripheral blood, being this lower than the sensitivity threshold of ELISPOT/ELISA assays we have used.

The acquisition of tolerance in children who had an IgEmediated form of CMA was associated with a profile of peripheral blood secondary responses characterized by a simultaneous reduction of IL-13 production and increased frequency of IFN- $\gamma$-releasing cells. Similarly, recent studies showed a Th1-like cytokine production profile in children after the complete resolution of peanut- (17) or egg-sensitized children (22).

Studies involving children have profound ethical restrictions and, in the case of our study, very limited blood samples were available. As a consequence, we were not able to further characterize the phenotype of peripheral blood cells reacting to b-LG. We found that proliferative responses were strongly reduced when blocking HLA-DQ and -DR molecules, in agreement with previous studies showing that allergens predominantly activate major histocompatibility complex-class II restricted CD4+ T cells $(3,23,24)$. Furthermore, our findings are in line with previous reports demonstrating the presence of food-specific $\mathrm{T}$ lymphocytes also in nonallergic, healthy subjects $(13,17,18,23,25)$. In this respect, it has been suggested that food protein-specific $\mathrm{T}$ cells may be produced as part of a normal immune response, and their presence is not restricted to a clinical manifestation of FA. Tsuge et al. (13) reported that the presence of CMP-specific, T-cell responses does not produce CMA per se, because either Th1, Th2, and Treg T cell clones reactive to allergens have been described in both healthy and allergic subjects. This suggests that the onset of allergic disease strictly depends on a delicate balance between effector and regulatory cell subtypes. Interestingly, a recent study reported that b-LG is able to activate both Treg and Th2 cells in PBMCs of CMA allergic children (26).

Although immune mechanisms underlying the acquisition of tolerance to food allergens remain poorly understood, several studies reported a key role of CD4+CD25 + Treg cells in children who outgrew CMA $(15,16)$. In addition, it has been suggested that also IL-10-producing Tr1 cells have an important role in maintaining tolerance to food antigens $(21,27)$. We found a marked production of IL-10 in PBMCs on stimulation with b-LG in all four groups analyzed, and nonallergic healthy children displayed the highest IL-10 level. Although we cannot exclude that the high IL-10 production to b-LG observed in all four analyzed groups could be partially because of an LPS-like activity of this allergen $(28,29)$, it remains interesting that healthy children showed the highest number of IL10-producing cells and that IL-10 was able to down-regulate the PBMCs' proliferative response to b-LG stimulation.

Collectively, our findings on the profile of immune response detected in shortly stimulated peripheral blood cells well agree with previous studies done with long-term T-cell lines or clones $(3,5,6)$ and support the use of fresh PBMCs to investigate the food-induced immune responses.

Understanding the immune mechanisms that underlie the onset of CMA, or mediate the tolerance in patients who have outgrown CMA, offers promise for a more accurate prognosis. Furthermore, possible intervention strategies could be more efficiently designed. Additional efforts are required to define the profile of immune responses occurring in the allergic condition or associated with the acquired immune tolerance to CMP. It is evident that the panel of immune markers investigated in this study have to be expanded, particularly it would be interesting to evaluate the role of Th17 and Th22 subsets in immune response in CMA, as demonstrated for other common allergies (30,31). The definition of the repertoire of immune responses detected with rapid in vitro assays would also offer a valid tool to monitor the evolution of one of the most frequent food allergies in childhood.

Acknowledgments. We thank Dr. GianVincenzo Barba for the statistic analysis and Dr. Luigi Cipriano and Mr. Clemente Meccariello for the excellent technical assistance. 


\section{REFERENCES}

1. Sicherer SH, Sampson HA 2009 Food allergy: recent advances in pathophysiology and treatment. Annu Rev Med 60:261-277

2. Lee LA, Burks W 2006 Food allergies: prevalence, molecular characterization, and treatment/prevention strategies. Annu Rev Nutr 26:539-565

3. Ruiter B, Trégoat V, M'rabet L, Garssen J, Bruijnzeel-Koomen CA, Knol EF, Hoffen E 2006 Characterization of T cell epitopes in alphas1-casein in cow's milk allergic, atopic and non-atopic children. Clin Exp Allergy 36:303-310

4. Picariello G, Ferranti P, Fierro O, Mamone G, Caira S, Di Luccia A, Monica S, Addeo F 2010 Peptides surviving the simulated gastrointestinal digestion of milk proteins: biological and toxicological implications. J Chromatogr B Analyt Technol Biomed Life Sci 878:295-308

5. Tiemessen MM, Van Ieperen-Van Dijk AG, Bruijnzeel-Koomen CA, Garssen J, Knol EF, Van Hoffen E 2004 Cow's milk-specific T-cell reactivity of children with and without persistent cow's milk allergy: key role for IL-10. J Allergy Clin Immunol 113:932-939

6. Schade RP, Van Ieperen-Van Dijk AG, Van Reijsen FC, Versluis C, Kimpen JL, Knol EF, Bruijnzeel-Koomen CA, Van Hoffen E 2000 Differences in antigenspecific T-cell responses between infants with atopic dermatitis with and without cow's milk allergy: relevance of TH2 cytokines. J Allergy Clin Immunol 106:11551162

7. Schade RP, Van Ieperen-Van Dijk AG, Versluis C, Van Reijsen FC, Kimpen JL, Bruijnzeel-Koomen CA, Knol EF, Van Hoffen E 2002 Cell-surface expression of CD25, CD26, and CD30 by allergen-specific T cells is intrinsically different in cow's milk allergy. J Allergy Clin Immunol 109:357-362

8. Tiemessen MM, Kunzmann S, Schmidt-Weber CB, Garssen J, Bruijnzeel-Koomen CA, Knol EF, van Hoffen E 2003 Transforming growth factor-beta inhibits human antigen-specific $\mathrm{CD} 4+\mathrm{T}$ cell proliferation without modulating the cytokine response. Int Immunol 15:1495-1504

9. Ruiter B, Rozemuller EH, van Dijk AJ, Garssen J, Bruijnzeel-Koomen CA, Tilanus MG, Knol EF, van Hoffen E 2007 Role of human leucocyte antigen DQ in the presentation of $\mathrm{T}$ cell epitopes in the major cow's milk allergen alphas1-casein. Int Arch Allergy Immunol 143:119-126

10. Kondo M, Kaneko H, Fukao T, Suzuki K, Sakaguchi H, Shinoda S, Kato Z, Matsui E, Teramoto T, Nakano T, Kondo N 2008 The response of bovine betalactoglobulin-specific T-cell clones to single amino acid substitution of T-cell core epitope. Pediatr Allergy Immunol 19:592-598

11. Inoue R, Matsushita S, Kaneko H, Shinoda S, Sakaguchi H, Nishimura Y, Kondo N 2001 Identification of beta-lactoglobulin-derived peptides and class II HLA molecules recognized by $\mathrm{T}$ cells from patients with milk allergy. Clin Exp Allergy 31:1126-1134

12. Beyer K, Castro R, Birnbaum A, Benkov K, Pittman N, Sampson HA 2002 Human milk-specific mucosal lymphocytes of the gastrointestinal tract display a $\mathrm{TH} 2$ cytokine profile. J Allergy Clin Immunol 109:707-713

13. Tsuge I, Kondo Y, Tokuda R, Kakami M, Kawamura M, Nakajima Y, Komatsubara R, Yamada K, Urisu A 2006 Allergen-specific helper T cell response in patients with cow's milk allergy: simultaneous analysis of proliferation and cytokine production by carboxyfluorescein succinimidyl ester dilution assay. Clin Exp Allergy 36:15381545

14. Crittenden RG, Bennett LE 2005 Cow's milk allergy: a complex disorder. J Am Coll Nutr 24:582S-591S
15. Karlsson MR, Rugtveit J, Brandtzaeg P 2004 Allergen-responsive CD4+CD25+ regulatory $\mathrm{T}$ cells in children who have outgrown cow's milk allergy. J Exp Med 199:1679-1688

16. Shreffler WG, Wanich N, Moloney M, Nowak-Wegrzyn A, Sampson HA 2009 Association of allergen-specific regulatory $\mathrm{T}$ cells with the onset of clinical tolerance to milk protein. J Allergy Clin Immunol 123:43-52

17. Akdis M, Verhagen J, Taylor A, Karamloo F, Karagiannidis C, Crameri R, Thunberg S, Deniz G, Valenta R, Fiebig H, Kegel C, Disch R, Schmidt-Weber CB, Blaser K, Akdis CA 2004 Immune responses in healthy and allergic individuals are characterized by a fine balance between allergen-specific T regulatory 1 and $\mathrm{T}$ helper 2 cells. J Exp Med 199:1567-1575

18. Turcanu V, Maleki SJ, Lack G 2003 Characterization of lymphocyte responses to peanuts in normal children, peanut-allergic children, and allergic children who acquired tolerance to peanuts. J Clin Invest 111:1065-1072

19. Maggi L, Santarlasci V, Liotta F, Frosali F, Angeli R, Cosmi L, Maggi E, Romagnani S, Annunziato F 2007 Demonstration of circulating allergen-specific CD4+CD25highFoxp3+ T-regulatory cells in both nonatopic and atopic individuals. J Allergy Clin Immunol 120:429-436

20. Berni Canani R, Ruotolo S, Discepolo V, Troncone R 2008 The diagnosis of food allergy in children. Curr Opin Pediatr 20:584-589

21. Gianfrani C, Levings MK, Sartirana C, Mazzarella G, Barba G, Zanzi D, Camarca A, Iaquinto G, Giardullo N, Auricchio S, Troncone R, Roncarolo MG 2006 Gliadin-specific type 1 regulatory $\mathrm{T}$ cells from the intestinal mucosa of treated celiac patients inhibit pathogenic T cells. J Immunol 177:4178-4186

22. Ng TW, Holt PG, Prescott SL 2002 Cellular immune responses to ovalbumin and house dust mite in egg-allergic children. Allergy 57:207-214

23. Sakaguchi H, Inoue R, Kaneko H, Watanabe M, Suzuki K, Kato Z, Matsushita S, Kondo N 2002 Interaction among human leucocyte antigen-peptide-T cell receptor complexes in cow's milk allergy: the significance of human leucocyte antigen and T cell receptor-complementarity determining region 3 loops. Clin Exp Allergy 32:762770

24. Kondo N, Fukutomi O, Agata H, Motoyoshi F, Shinoda S, Kobayashi Y, Kuwabara N, Kameyama T, Orii T 1993 The role of T lymphocytes in patients with foodsensitive atopic dermatitis. J Allergy Clin Immunol 91:658-668

25. Hoffman KM, Ho DG, Sampson HA 1997 Evaluation of the usefulness of lymphocyte proliferation assays in the diagnosis of allergy to cow's milk. J Allergy Clin Immunol 99:360-366

26. Savilahti EM, Karinen S, Salo HM, Klemetti P, Saarinen KM, Klemola T, Kuitunen M, Hautaniemi S, Savilahti E, Vaarala O 2010 Combined T regulatory cell and Th2 expression profile identifies children with cow's milk allergy. Clin Immunol 136:16-20

27. Hawrylowicz CM, O'Garra A 2005 Potential role of interleukin-10-secreting regulatory T cells in allergy and asthma. Nat Rev Immunol 5:271-283

28. Brix S, Bovetto L, Fritsché R, Barkholt V, Frøkiaer H 2003 Immunostimulatory potential of beta-lactoglobulin preparations: effects caused by endotoxin contamination. J Allergy Clin Immunol 112:1216-1222

29. Yamazaki K, Murray JA, Kita H 2008 Innate immunomodulatory effects of cereal grains through induction of IL-10. J Allergy Clin Immunol 121:172-178

30. Oseroff C, Sidney J, Kotturi MF, Kolla R, Alam R, Broide DH, Wasserman SI, Weiskopf D, McKinney DM, Chung JL, Petersen A, Grey H, Peters B, Sette A 2010 Molecular determinants of $\mathrm{T}$ cell epitope recognition to the common Timothy grass allergen. J Immunol 185:943-955

31. Souwer Y, Szegedi K, Kapsenberg ML, de Jong EC 2010 IL-17 and IL-22 in atopic allergic disease. Curr Opin Immunol 22:821-826 